\title{
Ecological Risk Assessment
}

\section{Accumulation of Rare Earth Elements in Corn after Agricultural Application}

\author{
Zijian Wang,* Dingfang Liu, Peng Lu, and Chunxia Wang
}

\begin{abstract}
Using both pot and plot experiments, the dose-dependent accumulation of rare earth elements (REs) in corn (Zea mays L.) after application of an agricultural REs mixture was measured. In the pot experiment, the dose-dependent accumulation of REs in corn root and stem was observed, but it could not be detected in corn leaf under the dosage of $20 \mathrm{mg} \mathrm{REs} \mathrm{kg}{ }^{-1}$ soil (oven-dry mass). The non-observed effect concentration (NOEC) for accumulation of REs in corn seedling

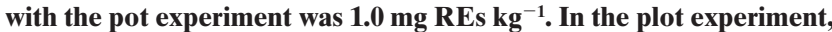
the dose-dependent accumulation was observed at an early stage after

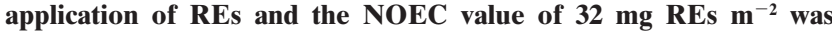
obtained. At harvest, no dose-dependent accumulation of REs was observed in any part of the corn. These results can be confirmed by the fingerprinting analysis based on the differences between La to RE ratios in the REs mixture and in pot or plot soil. We observed that the plant shows no preference on individual $\mathrm{RE}$ and the results of fingerprinting indicated clearly the incorporation of exogenous REs in plant tissues, in a similar manner as that observed in the dosedependent distribution of RE concentrations. The results indicated also a translocation process of REs from plant root to leaf when applied to soil or from leaf to root when applied to leaf. A homeostatic regulation mechanism for excessive uptake of REs in plants is suggested to regulate the concentrations of REs in the plant.
\end{abstract}

$\mathrm{R}^{\mathrm{n}}$ ARE earth elements (REs) frequently occur together in rare earth minerals and have similarities in ionic radii and chemical activities (Henderson, 1984). Although they are called rare earth elements because of their similarity to the earth (i.e., magnesia, lime, etc.), REs are not at all rare but represent as a group the 15th most abundant component of the earth's crust (Brown et al., 1990).

China has the largest reserves of REs in the world, representing approximately $80 \%$ of the known pool (Jackson, 1985). Application of REs in agriculture has been carried out intensively since 1972, aiming at increasing crop yields (Brown et al., 1990; Asher, 1991; Xiong, 1995). With this regard, many research works have been done to show the beneficial effects of REs on plant growth and soil properties. For example, REs were found to improve the bioavailability of calcium and manganese in soil (Chang, 1991), to stimulate the synthesis of chlorophyll (Guo, 1988), to promote seedling development (Chang, 1991; Wu et al., 1983), and to stimulate root and shoot growth in crops such as wheat (Triticum aestivum L.), cucumber (Cucumis sati-

State Key Lab. of Environmental Aquatic Chemistry, Research Center for Eco-Environmental Science, P.O. Box 2871, Beijing 100085, P.R. China. Received 5 Apr. 1999. *Corresponding author (wangzj@ mail.rcees.ac.cn).

Published in J. Environ. Qual. 30:37-45 (2001). vus L.), soybean [Glycine $\max (\mathrm{L}$.$) Merr.], and corn$ (Wu et al., 1983, 1985). Much less work has been done on the adverse effects of REs.

Recently, more and more attention has been given to the adverse effects of long-term RE application (Liu et al., 1997b,c; Todorovsky et al., 1997) and to the likely increase of environmental contamination from widespread industrial and agricultural uses of REs in the near future (Volkh et al., 1990). For example, concerns exist on the harmful effects of REs on the integrity of soil ecosystems (Ichihashi et al., 1992; Wang et al., 1997; Liu et al., 1997b,c) and on their potential toxicity for aquatic systems (Boger et al., 1997).

Many studies have reported RE accumulation in different types of cereal crops (Liu et al., 1997a; Lao et al., 1996; Dong et al., 1992; Wu et al., 1983) or in the different parts of plants (Liu et al., 1997a; Lao et al., 1996; Qi et al., 1984; Sun and Li, 1990). Reports also can be found on the time-dependent accumulation of REs in plants after their agricultural application (Zhang et al., 1993; Liu et al., 1997b,c). Unfortunately, these studies have been carried out mostly at a single concentration level and there has been no dose-effect relationship reported up to now. In addition, the reported behavior of REs in soil-plant systems is often contradictory (Peng and Wang, 1995) and very little information has been given so far on the potential accumulation of REs in edible parts of plants under the present application practices, where an REs mixture is being applied through foliage dressing.

In this work, the dose-dependent accumulation of REs in corn was examined using pot and plot experiments after application of the REs mixture.

\section{MATERIALS AND METHODS}

\section{Pot Experiment}

The soil used in the pot experiment was sampled from an agricultural land in Changping County $(100 \mathrm{~km}$ north of Beijing). The soil is a Luvisol (FAO soil classification) and the basic properties of the soil are shown in Table 1. This type of soil represents one of the major soil types in the middle parts of China where REs have been applied intensively. The content of individual REs and the ratio of La to REs in the soils are given in Table 2. Concentrations of REs in the pot soil were higher than in the plot soil (Table 2) because of the intensive application of different types of fertilizer for years, including the REs mixture.

The pot experiment was carried out following the OECD guideline for testing of chemicals (OECD, 1984). Each $0.5 \mathrm{~kg}$

Abbreviations: NOEC, non-observed effect concentration; RE, rare earth element. 
Table 1. Basic properties of the soils used in pot and plot experiments.

\begin{tabular}{|c|c|c|c|c|c|c|c|c|}
\hline & \multicolumn{4}{|c|}{ Composition } & \multicolumn{4}{|c|}{ Physiochemical properties } \\
\hline & Sand & Loam & Clay & Organic mater & pH & $\begin{array}{l}\text { Cation exchange } \\
\text { capacity }\end{array}$ & $\begin{array}{c}\text { Available } \\
\text { nitrogen }\end{array}$ & $\begin{array}{c}\text { Available } \\
\text { phosphorous }\end{array}$ \\
\hline & $\longrightarrow$ & . & $\%$ & - & & $\mathrm{cmol} \mathrm{kg}^{-1}$ & $\longrightarrow$ & $3^{-1} \dagger$ \\
\hline \multirow{2}{*}{$\begin{array}{l}\text { Soils used in pot } \\
\text { experiment } \\
\text { Soils used in plot } \\
\text { experiment }\end{array}$} & 24.4 & 42.0 & 34.0 & 1.35 & 7.25 & - & 17.7 & 11.3 \\
\hline & 28.6 & 51.2 & 20.2 & 0.80 & 7.70 & 16.0 & 21.3 & 12.6 \\
\hline
\end{tabular}

$\dagger$ Concentration in all tables is expressed on an oven-dried mass basis.

of soil was put into a $12-\times 12-\mathrm{cm}$ plastic pot and seeds of spring corn (cv. Zhongxia-9) were planted at a density of 15 seeds per pot and subsequently thinned to 10 plants per pot. The plants were cultured in a growth chamber with a light intensity of $2500 \mathrm{~lx}$. A commercial REs mixture, known as Chang-Le by Chinese farmers, was obtained from the China Center for Agricultural Application of REs. The composition of the REs mixture and the La to RE ratio are given in Table 2.

Application of REs was carried out after the seeds had sprouted and grown up for a few days. The weighted REs mixture was dissolved in distilled water and the prepared solution was sprayed evenly to the soils to obtain final concen-

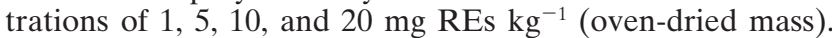
Plants were sampled 2 wk after application. During growth, soil humidity was maintained by adding $50 \mathrm{~mL}$ deionized water per pot every $3 \mathrm{~d}$.

\section{Plot Experiment}

The plot experiment was carried out in a northern suburb of Beijing. The soil used in the plot experiment was also a Luvisol (FAO soil classification). Its basic properties are similar to the soil used in the pot experiment (Table 1) but the content of individual REs and the sum of REs were obviously lower than the soil used in the pot experiment, while the ratios of La to RE were similar (Table 2). Unlike the land where pot soil was sampled, the land for the plot experiment had been abandoned for years.

Four plots of $12 \mathrm{~m}^{2}$ each were used in the plot experiment. These plots were planted with spring corn (cv. Zhongxia-9) and REs (Chang-Le) were applied at 16, 32, and $64 \mathrm{mg}$ REs $\mathrm{m}^{-2}$. The prepared solution of REs was foliage-dressed to plant leaves during the seedling period, similar to the method used by Chinese farmers. The dosages found in the treatment groups corresponded to one-, two-, and fourfold higher than the practical dosages of REs used by Chinese farmers. One plot was set as the control where only water was applied. One aim of the study was to evaluate the accumulation of REs in the different parts of corn under current practical RE application.

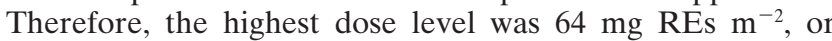
fourfold higher than the amount used in farming practices. To help find the dose-dependent relationship between REs applied and REs in plants, a fingerprinting analysis based on the $\mathrm{La}$ to $\mathrm{RE}$ ratios was necessary, at least to confirm the incorporation of exogenous REs in the different parts of the plant. The fingerprinting analysis was possible because the ratios of $\mathrm{La}$ to $\mathrm{RE}$ in the $\mathrm{REs}$ mixture (i.e., $\mathrm{La} / \mathrm{Ce}=2.1$ ) were much higher than those in soils (i.e., $\mathrm{La} / \mathrm{Ce}=0.38-0.45$, Table 2 ). The concentrations of REs and the ratios of La to RE in the plot soil are shown in Table 2.

The application was performed at the shooting growth stage (ca. $90 \mathrm{~d}$ ). Plants were sampled $2 \mathrm{~d}$ before application and at the sixth and 57th day after application. Plant flower and grain were sampled at harvest (57th day after application).

\section{Sample Preparation and Analysis}

Four duplicate fresh plants were harvested, cleaned, and washed with deionized water three times. The whole plant was separated into root, stem, and leaf in the pot experiment and into root, stem, leaf, flower, and grain in the plot experiment. These subplant samples were dried in a microwave oven and ground in a 1-mm sieve. Each 0.5 -g plant or subplant sample was treated with $8 \mathrm{~cm}^{3}$ of a mixed oxidizing solution (15 mol L ${ }^{-1} \mathrm{HNO}_{3}$ and $9 \mathrm{~mol} \mathrm{~L}^{-1} \mathrm{H}_{2} \mathrm{O}_{2}$, v/v) and digested for $30 \mathrm{~min}$ at $2600 \mathrm{kPa}$ (80 psi) in a MDS-2000 microwave oven (CEM Corp., Matthews, NC). The sample was diluted to a final volume of $25 \mathrm{~mL}$ with deionized water before analysis.

Concentrations of REs in each sample were determined by a Plasma Quard II ICP-MS spectrometer (Fishons Instruments Elemental Analysis, Cheshire, UK) operated at a sampling rate of $1.0 \mathrm{~mL} \mathrm{~min}^{-1}$ with a measuring time of $40 \mathrm{~s}$. Indium $\left.{ }^{115} \mathrm{In}\right)$ was used as an internal standard for calibrating the instrument. To calibrate the analysis, the stock solution of each

Table 2. Concentration $\dagger$ of individual rare earth elements (REs) and the ratio of La to RE in the REs mixture and in pot and plot soils.

\begin{tabular}{|c|c|c|c|c|c|c|}
\hline \multirow[b]{2}{*}{ Element } & \multicolumn{2}{|c|}{ REs mixture $\ddagger$} & \multicolumn{2}{|c|}{ Pot Soil } & \multicolumn{2}{|c|}{ Plot Soil } \\
\hline & Concentration & $\begin{array}{c}\text { La to } R E \\
\text { ratio }\end{array}$ & Concentration & $\begin{array}{l}\text { La to } R E \\
\text { ratio }\end{array}$ & Concentration & $\begin{array}{c}\text { La to } R E \\
\text { ratio }\end{array}$ \\
\hline & $\mathbf{g ~ k g}^{-1}$ & & $\mathbf{m g ~ k g} \mathbf{~}^{-1}$ & & $\mathbf{m g ~ k g ^ { - 1 }}$ & \\
\hline La & 133 & & 52.6 & & 31.2 & \\
\hline $\mathrm{Ce}$ & 63.3 & 2.1 & 137.5 & 0.38 & 69.1 & 0.45 \\
\hline Pr & 26.4 & 5.0 & 14.4 & 3.65 & 7.9 & 3.95 \\
\hline Nd & 40.0 & 3.3 & 43.3 & 1.21 & 28.5 & 1.10 \\
\hline Sm & 4.0 & 33.0 & 9.4 & 5.60 & 5.3 & 5.89 \\
\hline Gd & 2.5 & 53.9 & 10.2 & 5.16 & 4.6 & 6.78 \\
\hline Dy & 0.05 & 2484 & 8.3 & 6.34 & 3.5 & 8.91 \\
\hline REs§ & 268 & & 275.7 & & 150.2 & \\
\hline
\end{tabular}

$\dagger$ Concentration is expressed on an oven-dried mass basis.

+ REs mixture is used as fertilizer by Chinese farmers and contains common salts such as $\mathrm{NaCl}_{1} \mathrm{CaSO}_{4}$, etc.

$\S$ Sum of La, Ce, Pr, Nd, Sm, Gd, and Dy. 

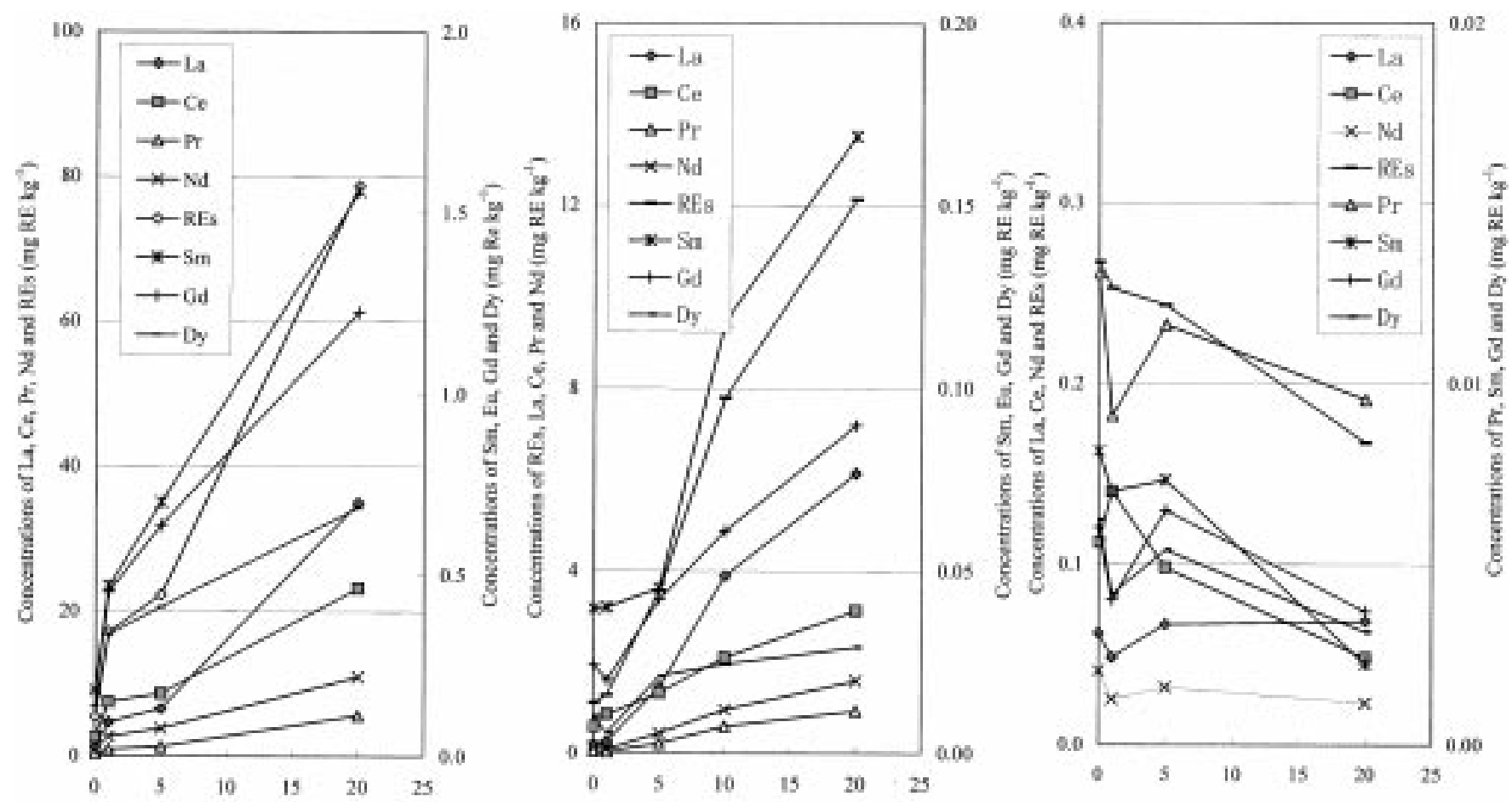

Applied REs Coocentration ( $\mathrm{mg}$ REs $\mathrm{kg}^{-1}$ soil)

Fig. 1. Concentrations of rare earth elements (REs) in corn roots, stems, and leaves after application of the REs mixture in the pot experiment. Data are expressed as the average concentration $(n=4)$. Standard deviations are given in Tables 3 to 5 , respectively. The RE concentrations represent the added concentration of $\mathrm{La}, \mathrm{Ce}, \mathrm{Pr}, \mathrm{Nd}, \mathrm{Sm}, \mathrm{Gd}$, and Dy.

RE (1000 $\left.\mathrm{mg} \mathrm{L}^{-1}\right)$ was obtained from the National Research Center for Certified Reference Materials, Beijing, China. The standard solution of mixed REs was prepared by diluting the stock solutions in two steps with $1 \%$ concentrated $\mathrm{HNO}_{3}$.

The accuracy of the elemental analysis was checked by the determination of REs in the certified reference materials (GSS-1 of soils and GBW 07605 of tea from the National Research Center for Certified Reference Materials, Beijing, China). The results deviated by less than $10 \%$ from the accepted values (Zhang and Shan, 1997). The precision of this digestion method was evaluated by analyzing four duplicate plant samples. It was found that the relative standard deviation (RSD) was below $10 \%$ for the various individual REs.

A statistical data analysis was performed by the one-way
ANOVA analysis using SPSS Version 9.0 (SPSS, 1999). Analysis was performed for any two experimental groups.

\section{RESULTS AND DISCUSSION}

\section{Accumulation of Rare Earth Elements in the Different Parts of Corn in the Pot Experiment}

A total of 14 REs, namely $\mathrm{La}, \mathrm{Ce}, \mathrm{Pr}, \mathrm{Nd}, \mathrm{Sm}, \mathrm{Eu}$, Gd, Tb, Dy, Ho, Er, Tm, Yb, and Lu, were analyzed. Concentrations of individual REs varied by several orders of magnitude. In the discussion, only the REs, La, $\mathrm{Ce}, \mathrm{Pr}, \mathrm{Nd}, \mathrm{Sm}, \mathrm{Gd}$, and Dy are included. The added concentration of these seven REs represented more

Table 3. Concentration $\dagger$ and ratio of La to rare earth elements (REs) in the corn-root in the pot experiment.

\begin{tabular}{|c|c|c|c|c|c|c|c|c|}
\hline & \multicolumn{8}{|c|}{ Applied concentration (mg RE $\mathbf{k g}^{-1}$ soil) } \\
\hline & \multicolumn{2}{|l|}{$\mathbf{0}$} & \multicolumn{2}{|l|}{1} & \multicolumn{2}{|l|}{5} & \multicolumn{2}{|c|}{20} \\
\hline & Concentration $\doteqdot$ & La/RE & Concentration $\ddagger$ & La/RE & Concentration $\ddagger$ & La/RE & Concentration $\uparrow$ & La/RE \\
\hline & mg RE kg $\mathbf{~}^{-1}$ & & mg RE $\mathbf{k g}^{-1}$ & & mg RE $\mathbf{k g}^{-1}$ & & mg RE kg $\mathbf{~}^{-1}$ & \\
\hline $\mathbf{L a}$ & $1.15 \pm 0.31$ & & $4.65 \pm 1.31 * *$ & & $6.54 \pm 5.81^{* * *}$ & & $35.0 \pm 3.50 * *$ & \\
\hline $\mathrm{Ce}$ & $2.59 \pm 0.33$ & 0.44 & $7.49 \pm 2.39 * *$ & $0.62 * *$ & $8.63 \pm 6.75 * *$ & $0.76 * *$ & $23.2 \pm 2.32 * *$ & $1.51 * *$ \\
\hline Pr & $0.27 \pm 0.07$ & 4.24 & $0.92 \pm 0.16^{* *}$ & $\mathbf{5 . 0 8}^{* * *}$ & $1.32 \pm 1.11 * *$ & $4.97 * *$ & $5.62 \pm 0.56 * *$ & $6.23 * *$ \\
\hline Nd & $0.89 \pm 0.26$ & 1.30 & $2.69 \pm 0.33^{* *}$ & $1.73 * *$ & $\mathbf{3 . 8 0} \pm \mathbf{3 . 0 5}^{*}$ 水 & $1.72 * *$ & $11.0 \pm 1.10 * *$ & 3.19** \\
\hline Sm & $0.18 \pm 0.03$ & 6.29 & $0.47 \pm 0.09 * *$ & $9.90 * *$ & $\mathbf{0 . 7 0} \pm \mathbf{0 . 4 9} * *$ & $9.34 * *$ & $1.56 \pm 0.16 * *$ & $22.4^{* * *}$ \\
\hline Gd & $0.18 \pm 0.04$ & 6.51 & $0.45 \pm 0.05 * *$ & $10.3 * *$ & $\mathbf{0 . 6 4} \pm \mathbf{0 . 4 9} * *$ & $10.3 * *$ & $1.23 \pm 0.12 * *$ & $28.6^{* * *}$ \\
\hline Dy & $0.14 \pm 0.05$ & 8.37 & $0.34 \pm 0.05^{* *}$ & $13.8 * *$ & $0.41 \pm 0.28^{* *}$ & $15.9 * *$ & $0.69 \pm 0.07 * *$ & $51.0 * *$ \\
\hline REs§ & $5.47 \pm \mathbf{1 . 1 2}$ & & $17.2 \pm 3.9 * *$ & & $22.3 \pm 18.1^{* *}$ & & $78.7 \pm 7.8 * *$ & \\
\hline
\end{tabular}

** Significant at the 0.01 probability level.

$\dagger$ Concentration is expressed on an oven-dried mass basis.

+ Average \pm standard deviation, $n=4$.

$\S$ Sum of La, Ce, Pr, Nd, Sm, Gd, and Dy. 
Table 4. Concentration $\dagger$ and ratio of La to rare earth elements (RE) in the corn-stem in the pot experiment.

\begin{tabular}{|c|c|c|c|c|c|c|c|c|c|c|}
\hline \multirow[b]{3}{*}{$\underline{\mathbf{R E}}$} & \multicolumn{10}{|c|}{ Applied concentration (mg RE $\mathrm{kg}^{-1}$ soil) } \\
\hline & \multicolumn{2}{|l|}{$\mathbf{0}$} & \multicolumn{2}{|l|}{1} & \multicolumn{2}{|l|}{5} & \multicolumn{2}{|l|}{10} & \multicolumn{2}{|l|}{20} \\
\hline & Concentration & $\mathbf{L a} / \mathbf{R E}$ & Concentration $\leftarrow$ & $\mathbf{L a} / \mathbf{R E}$ & Concentration & $\mathbf{L a} / \mathbf{R E}$ & Concentration $\ddagger$ & $\mathbf{L a} / \mathbf{R E}$ & Concentration & $\mathbf{L a} / \mathbf{R E}$ \\
\hline & $\operatorname{mg~RE~} \mathrm{kg}^{-1}$ & & $\operatorname{mg~RE~} \mathbf{k g}^{-1}$ & & $\operatorname{mg~RE} \mathbf{k g}^{-1}$ & & $\operatorname{mg~RE} \mathbf{k g}^{-1}$ & & $\operatorname{mg~RE} \mathbf{k g}^{-1}$ & \\
\hline $\mathbf{L a}$ & $\mathbf{0 . 1 8} \pm \mathbf{0 . 0 0}$ & & $0.25 \pm 0.08 * *$ & & $1.45 \pm 0.84 * *$ & & $3.88 \pm 2.45 * *$ & & $6.14 \pm 1.06 * *$ & \\
\hline $\mathrm{Ce}$ & $\mathbf{0 . 5 8} \pm 0.07$ & 0.31 & $\mathbf{0 . 8 5} \pm \mathbf{0 . 1 5} * *$ & 0.29 & $1.32 \pm 0.06 * *$ & $1.10 * *$ & $\mathbf{2 . 1 0} \pm \mathbf{0 . 9 5} * *$ & $1.85 * *$ & $\mathbf{3 . 1 4} \pm \mathbf{0 . 6 3} * *$ & $1.96 * *$ \\
\hline Pr & $\mathbf{0 . 0 4} \pm \mathbf{0 . 0 0}$ & 4.40 & $\mathbf{0 . 0 3} \pm \mathbf{0 . 0 1}$ & $7.20 * *$ & $0.21 \pm \mathbf{0 . 1 2} * *$ & $6.78 * *$ & $\mathbf{0 . 5 9} \pm \mathbf{0 . 3 4} * *$ & $6.63 * *$ & $0.93 \pm 0.20 * *$ & $6.57 * *$ \\
\hline Nd & $\mathbf{0 . 1 5} \pm 0.03$ & 1.18 & $\mathbf{0 . 0 8} \pm \mathbf{0 . 0 1}$ & $3.01 * *$ & $0.44 \pm 0.18 * *$ & 3.33** & $\mathbf{0 . 9 5} \pm \mathbf{0 . 5 4} * *$ & $4.08 * *$ & $1.59 \pm 0.35 * *$ & $3.85 \%$ \\
\hline Sm & $0.04 \pm 0.01$ & 4.54 & $0.04 \pm 0.001$ & $6.25 * *$ & $0.05 \pm 0.01$ & 32.1** & $\mathbf{0 . 1 2} \pm \mathbf{0 . 0 7} * *$ & $32.8^{* * *}$ & $\mathbf{0 . 1 7} \pm \mathbf{0 . 0 4} * *$ & $36.3 * *$ \\
\hline Gd & $\mathbf{0 . 0 2} \pm \mathbf{0 . 0 0 3}$ & $\mathbf{7 . 4}$ & $0.02 \pm 0.01$ & $12.5^{* * *}$ & $0.04 \pm 0.01$ & $34.4^{* *}$ & $\mathbf{0 . 0 6} \pm \mathbf{0 . 0 2} * *$ & 63.8** & $\mathbf{0 . 0 9} \pm \mathbf{0 . 0 3} * *$ & $68.3 * *$ \\
\hline Dy & $0.01 \pm 0.001$ & 18.0 & $\mathbf{0 . 0 1} \pm \mathbf{0 . 0 0 3}$ & $45.6 * *$ & $0.02 \pm 0.001$ & 69.0** & $\mathbf{0 . 0 2} \pm \mathbf{0 . 0 1} * *$ & $158.7 * *$ & $\mathbf{0 . 0 3} \pm \mathbf{0 . 0 0 4} *$ & $211.2 * *$ \\
\hline REs§ & $1.10 \pm 0.09$ & & $1.28 \pm 0.24$ & & $3.56 \pm 1.22 * *$ & & $7.79 \pm 4.36^{* *}$ & & $12.13 \pm 2.33 * *$ & \\
\hline
\end{tabular}

** Significant at the 0.01 probability level.

$\uparrow$ Concentration is expressed on an oven-dried mass basis.

+ Average \pm standard deviation, $n=4$.

$\S$ Sum of La, Ce, Pr, Nd, Sm, Gd and Dy.

than $90 \%$ of the 14 total REs. In comparison with La, $\mathrm{Ce}, \mathrm{Pr}$, and $\mathrm{Nd}$, concentrations of other REs were much smaller and the calculated La to RE ratios of these REs became ambiguous. Therefore, only the La to RE ratios for four major REs are considered valid for discussion and the other La to RE ratios are kept for reference only.

Concentrations of REs in corn roots, stems, and leaves after application of the different doses of REs are shown in Fig. 1. Concentrations of REs were much higher in plant roots and were followed by a sharp increase at $1 \mathrm{mg} \mathrm{RE} \mathrm{kg}^{-1}$ (Fig. 1). It could be reasonably assumed that the total REs in plant roots included not only REs absorbed, but also REs adsorbed on surfaces of the root system. Concentrations of REs in corn stems were about one-sixth of those in roots and the dosedependent behaviors were different from those observed in plant roots (i.e., a flat phase at lower doses and a shape linear increase phase at higher doses). This observation is supported by previous results (Liu et al., 1997b; Ichihashi et al., 1992). Obviously, only a small part of REs absorbed by the root could be transported to the stem. A significant increase in concentrations of REs in corn stems could be observed for treatments

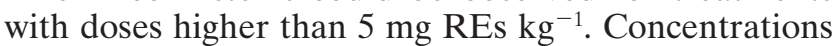
of REs in corn leaves were much lower than those in roots or stems and there was no significant dose-dependent accumulation in the plant leaves.
In the control, concentrations of individual REs in subplant samples ranked in the order of $\mathrm{Ce}>\mathrm{La}>$ $\mathrm{Nd}>\mathrm{Pr}>\mathrm{Sm}$ (Tables 3-5). The same orders of RE concentrations could be observed in pot and plot soils (Table 2). As shown in Tables 3 and 4, concentrations of REs in plant roots and stems were significantly higher than those in the control after application of $1 \mathrm{mg}$ REs $\mathrm{kg}^{-1}(p<0.05)$. When REs were applied in doses equal to or higher than $5 \mathrm{mg} \mathrm{REs} \mathrm{kg}{ }^{-1}$, a reversed concentration order of $\mathrm{La}>\mathrm{Ce}>\mathrm{Nd}>\mathrm{Pr}>\mathrm{Sm}$ was observed (Tables 3 and 4). This order was the same as that in the applied REs mixture (Table 2). The results indicate clearly the incorporation of exogenous REs into plant tissues. For example, the concentrations of $\mathrm{Ce}$ in pot and plot soils were 2.2 and 2.6 times higher than concentrations of La, respectively. On the other hand, the concentration of $\mathrm{La}$ in the REs mixture was 2.09 times higher than that of Ce. Therefore, a reverse concentration order between La and Ce could be found in subplant samples when the uptake of exogenous REs prevailed in plant tissues, assuming that the plant shows no preference on individual REs. This assumption will be examined later in the text.

Alternatively, the La to RE ratios could be used as a fingerprint to trace the origin of REs in the different parts of the plant. The calculated La to RE ratios for subplant samples from different treatments are shown in Tables 3 to 5. The La to RE ratios for the different

Table 5. Concentration $\dagger$ and ratio of La to rare earth elements (REs) in the corn-leaf in the pot experiment.

\begin{tabular}{|c|c|c|c|c|c|c|c|c|}
\hline \multirow[b]{3}{*}{$\mathbf{R E}$} & \multicolumn{8}{|c|}{ Applied concentration (mg RE $\mathbf{k g}^{-1}$ soil) } \\
\hline & \multicolumn{2}{|l|}{$\mathbf{0}$} & \multicolumn{2}{|l|}{1} & \multicolumn{2}{|l|}{5} & \multicolumn{2}{|c|}{20} \\
\hline & Concentration & $\mathbf{L a} / \mathbf{R E}$ & Concentration & $\mathbf{L a} / \mathbf{R E}$ & Concentration $\ddagger$ & $\mathbf{L a} / \mathbf{R E}$ & Concentration & $\mathbf{L a} / \mathbf{R E}$ \\
\hline & $\operatorname{mg~RE} \mathbf{k g}^{-1}$ & & $\operatorname{mg~RE~} \mathbf{k g}^{-1}$ & & $\operatorname{mg~RE} \mathbf{k g}^{-1}$ & & $\operatorname{mg~RE} \mathbf{k g}^{-1}$ & \\
\hline $\mathbf{L a}$ & $0.062 \pm 0.038$ & & $0.049 \pm 0.012$ & & $0.067 \pm 0.020$ & & $0.069 \pm 0.014$ & \\
\hline $\mathrm{Ce}$ & $0.112 \pm 0.074$ & 0.55 & $\mathbf{0 . 1 4 0} \pm \mathbf{0 . 1 0 9}$ & 0.35 & $\mathbf{0 . 0 9 8} \pm \mathbf{0 . 0 3 5}$ & 0.68 & $\mathbf{0 . 0 4 8} \pm \mathbf{0 . 0 0 6}$ & $1.43^{* * *}$ \\
\hline Pr & $\mathbf{0 . 0 1 3} \pm \mathbf{0 . 0 0 5}$ & 4.75 & $0.009 \pm 0.003$ & 5.38 & $0.012 \pm 0.004$ & 5.76 & $\mathbf{0 . 0 1 0} \pm \mathbf{0 . 0 0 1}$ & 7.21 $* *$ \\
\hline Nd & $\mathbf{0 . 0 4 1} \pm \mathbf{0 . 0 2 4}$ & 1.51 & $\mathbf{0 . 0 2 5} \pm \mathbf{0 . 0 1 2}$ & 1.94 & $\mathbf{0 . 0 3 2} \pm \mathbf{0 . 0 1 8}$ & 2.10 & $\mathbf{0 . 0 2 3} \pm \mathbf{0 . 0 0 7}$ & $2.96 * *$ \\
\hline Sm & $\mathbf{0 . 0 0 8} \pm \mathbf{0 . 0 0 3}$ & 7.62 & $\mathbf{0 . 0 0 7} \pm \mathbf{0 . 0 0 3}$ & 6.98 & $0.007 \pm 0.001$ & 9.14 & $\mathbf{0 . 0 0 2} \pm \mathbf{0 . 0 0 1}$ & 30.78** \\
\hline Gd & $\mathbf{0 . 0 0 6} \pm \mathbf{0 . 0 0 2}$ & 10.29 & $\mathbf{0 . 0 0 4} \pm \mathbf{0 . 0 0 2}$ & 12.2 & $\mathbf{0 . 0 0 6} \pm \mathbf{0 . 0 0 2}$ & 10.32 & $\mathbf{0 . 0 0 4} \pm \mathbf{0 . 0 0 1}$ & $18.65^{* *}$ \\
\hline Dy & $0.006 \pm 0.001$ & 9.96 & $0.004 \pm 0.002$ & 11.8 & $\mathbf{0 . 0 0 5} \pm \mathbf{0 . 0 0 2}$ & 12.41 & $\mathbf{0 . 0 0 3} \pm \mathbf{0 . 0 0 1}$ & 22.08 ** \\
\hline REs§ & $0.267 \pm \mathbf{0 . 1 5 8}$ & & $0.253 \pm 0.117$ & & $\mathbf{0 . 2 4 4} \pm \mathbf{0 . 0 7 4}$ & & $0.167 \pm \mathbf{0 . 0 1 2}$ & \\
\hline
\end{tabular}

** Significant at the 0.01 probability level.

$\dagger$ Concentration is expressed on an oven-dried mass basis.

Average \pm standard deviation, $n=4$.

$\S$ Sum of La, Ce, Pr, Nd, Sm, Gd and Dy. 
Table 6. Concentration ratios of plant to soil $\dagger$ for individual rare earth elements (REs) and REs in different plant parts in the pot experiment.

\begin{tabular}{|c|c|c|c|c|c|c|c|c|c|c|c|c|}
\hline & \multicolumn{12}{|c|}{ Concentration ratios of plant to soil } \\
\hline & \multicolumn{4}{|c|}{ Root } & \multicolumn{4}{|c|}{ Stem } & \multicolumn{4}{|c|}{ Leaf } \\
\hline & \multicolumn{4}{|c|}{ Applied concentration (mg RE $\mathrm{kg}^{-1}$ soil) } & \multicolumn{4}{|c|}{ Applied concentration (mg RE $\mathbf{k g}^{-1}$ soil) } & \multicolumn{4}{|c|}{ Applied concentration (mg RE $\mathrm{kg}^{-1}$ soil) } \\
\hline & $\mathbf{0}$ & 1 & 5 & 20 & $\mathbf{0}$ & 1 & 5 & 20 & $\mathbf{0}$ & 1 & 5 & 20 \\
\hline $\mathbf{L a}$ & 0.022 & 0.088 & 0.119 & 0.609 & 0.0034 & 0.0047 & 0.026 & 0.116 & 0.0012 & 0.0009 & 0.0012 & 0.0012 \\
\hline $\mathrm{Ce}$ & 0.019 & 0.054 & 0.062 & 0.166 & 0.0042 & 0.0062 & 0.010 & 0.023 & 0.0008 & 0.0010 & 0.0007 & 0.0003 \\
\hline Pr & 0.019 & 0.063 & 0.089 & 0.366 & 0.0028 & 0.0024 & 0.014 & 0.065 & 0.0009 & 0.0006 & 0.0008 & 0.0006 \\
\hline Nd & 0.020 & 0.062 & 0.086 & 0.245 & 0.0035 & 0.0019 & 0.010 & 0.037 & 0.0009 & 0.0006 & 0.0007 & 0.0005 \\
\hline Sm & 0.019 & 0.050 & 0.074 & 0.164 & 0.0042 & 0.0047 & 0.005 & 0.018 & 0.0009 & 0.0007 & 0.0008 & 0.0002 \\
\hline Gd & 0.017 & 0.044 & 0.062 & 0.119 & 0.0020 & 0.0022 & 0.004 & 0.009 & 0.0006 & 0.0004 & 0.0006 & 0.0004 \\
\hline Dy & 0.017 & 0.041 & 0.050 & 0.083 & 0.0012 & 0.0007 & 0.003 & 0.004 & 0.0007 & 0.0005 & 0.0007 & 0.0004 \\
\hline REs & 0.019 & 0.059 & 0.075 & 0.262 & 0.0038 & 0.0044 & 0.012 & 0.042 & 0.0009 & 0.0009 & 0.0008 & 0.0006 \\
\hline
\end{tabular}

$\dagger$ Concentration ratio of plant to soil $=$ concentration of $\mathrm{RE}$ in subplant sample/concentration of $\mathrm{RE}$ in soil.

parts of plants in control groups were quite similar to those in soil. This might imply that plant uptake of different REs from soil is proportional to RE concentrations in soil or that plants show no preference for individual REs. With increasing dosage levels of applied REs, the different La to RE ratios in plant roots and stems (Tables 3 and 4) increased and gradually approached those observed in the REs mixture (Table 2). This indicates clearly that when REs were applied, the excessive REs in plant roots and stems should come from the applied REs mixture rather than from the soil used in the experiment.

There was no significant increase in concentrations of individual REs in corn leaves after application of the different doses of REs ( $p>0.05$, Table 5). It seems that there was a limiting factor controlling the transport of REs from plant stems to leaves. On the other hand, the incorporation of exogenous REs in corn leaves could be deduced by the fingerprinting analysis (Table 5) when higher doses were applied. Therefore, there should be a replacement of REs from the soil by REs from the applied REs mixture in plant leaves after REs application.

The plant preference for individual REs could be illustrated by the respective concentration ratio of plant to soil, defined as the ratio of RE concentration in subplant samples to RE concentration in soil. The results presented in Table 6 show that the concentration ratio of individual REs in the different parts of the plants of the control groups was similar to that of REs. The results, together with the results obtained from the fingerprinting analysis (Tables 3-5), indicate that plants show no preference for individual REs from pot soil. When the REs mixture was applied, the concentration ratio increased with increasing doses of applied REs, but was not proportional to the increase of the total soil concentration of REs (soil REs plus exogenous REs). It could be reasonably assumed that REs in the REs mixture should be more available to plants, at least during the experimental period.
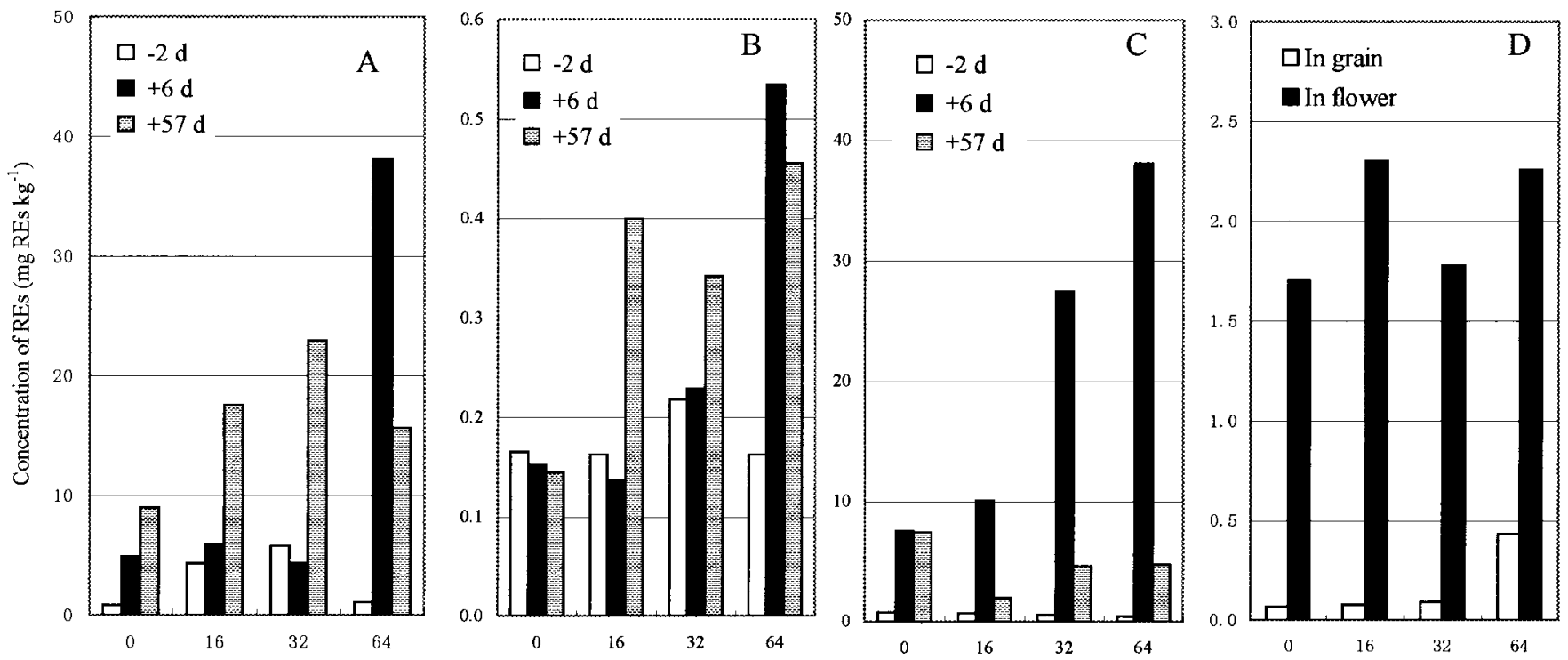

Applied REs Concentration (mg REs $\mathrm{m}^{-2}$ )

Fig. 2. Concentrations of rare earth elements (REs) in corn roots $(A)$, stems $(B)$, and leaves $(C)$ at different days after application of the REs mixture and in flower and grain $(D)$ at the day of harvest in the plot experiment. Bars represent the concentration of La, Ce, Pr, Nd, Sm, Gd, and Dy. 
Table 7. Concentration† and La to rare earth element (RE) ratio in corn leaf before and after applying different doses of REs in the plot experiment.

\begin{tabular}{|c|c|c|c|c|c|c|c|c|c|c|c|c|c|c|c|c|c|c|}
\hline \multirow[b]{4}{*}{$\mathbf{R E}$} & & & \multicolumn{8}{|c|}{$6 \mathrm{~d}$ after application } & \multicolumn{8}{|c|}{$57 \mathrm{~d}$ after application } \\
\hline & & & \multicolumn{8}{|c|}{ Applied concentration $\left(\mathrm{mg} \mathrm{m}^{-2}\right) \ddagger$} & \multicolumn{8}{|c|}{ Applied concentration $\left(\mathrm{mg} \mathrm{m}^{-2}\right)$} \\
\hline & \multicolumn{2}{|c|}{2 d before application $\S$} & \multicolumn{2}{|c|}{$\mathbf{0}$} & \multicolumn{2}{|c|}{16} & \multicolumn{2}{|c|}{32} & \multicolumn{2}{|c|}{64} & \multicolumn{2}{|c|}{$\mathbf{0}$} & \multicolumn{2}{|c|}{16} & \multicolumn{2}{|c|}{32} & \multicolumn{2}{|c|}{64} \\
\hline & Conc. & $\mathbf{L a} / \mathbf{R E}$ & Conc. & $\mathbf{L a} / \mathbf{R E}$ & Conc. & $\mathbf{L a} / \mathbf{R E}$ & Conc. & $\mathbf{L a} / \mathbf{R E}$ & Conc. & $\mathbf{L a} / \mathbf{R E}$ & Conc. & $\mathbf{L a} / \mathbf{R E}$ & Conc. & $\mathbf{L a} / \mathbf{R E}$ & Conc. & $\mathbf{L a} / \mathbf{R E}$ & Conc. & $\mathbf{L a} / \mathbf{R E}$ \\
\hline & $\mathbf{m g ~ k g ^ { - 1 }}$ & & $\mathrm{mg} \mathrm{kg}^{-1}$ & & $\mathrm{mg} \mathrm{kg}^{-1}$ & & $\mathrm{mg} \mathrm{kg}^{-1}$ & & $\mathbf{m g ~ k g}{ }^{-1}$ & & $\mathbf{m g ~ k g} \mathbf{~}^{-1}$ & & $\mathbf{m g ~ k g} \mathbf{~}^{-1}$ & & $\mathbf{m g ~ k g}^{-1}$ & & mg kg ${ }^{-1}$ & \\
\hline La & 0.13 & & 1.62 & & 5.37 & & 13.14 & & 18.5 & & 1.44 & & 0.43 & & $2.25 * *$ & & $2.06 * *$ & \\
\hline Ce & 0.24 & 0.52 & 3.39 & 0.48 & 2.44 & $2.20 * *$ & 7.11 & $1.85 * *$ & 10.0 & $1.84 * *$ & 3.31 & 0.44 & 0.88 & 0.48 & 1.26 & $1.79 * *$ & 1.45 & $1.42 * *$ \\
\hline Pr & 0.08 & 3.77 & 0.38 & 4.28 & 0.78 & $6.91 * *$ & 2.48 & $5.31 * *$ & 3.45 & 5.36 ** & 0.37 & 3.88 & 0.10 & 4.13 & 0.33 & $6.76^{* * *}$ & 0.32 & $6.37 * *$ \\
\hline Nd & 0.11 & 1.17 & 1.43 & 1.14 & 1.28 & $4.21 * *$ & 4.07 & $3.23 * *$ & 5.19 & $3.57 * *$ & 1.47 & 0.98 & 0.34 & 1.24 & 0.61 & $3.71 * *$ & 0.68 & $3.04 * *$ \\
\hline Sm & 0.02 & 7.91 & 0.25 & 6.41 & 0.12 & 44.9** & 0.39 & 33.9** & 0.51 & $36.2 * * *$ & 0.36 & 4.40 & 0.07 & 6.03 & 0.08 & $28.3^{* *} *$ & 0.09 & 22.2** \\
\hline Gd & 0.02 & 6.71 & 0.30 & 5.35 & 0.09 & $60.9 * *$ & 0.28 & $47.3 * *$ & 0.40 & 46.6** & 0.28 & 5.24 & 0.07 & 6.18 & 0.05 & 47.4** & 0.10 & $20.8 * *$ \\
\hline Dy & 0.01 & 9.87 & 0.16 & 10.2 & 0.01 & $401 * *$ & 0.01 & - & 0.01 & - & 0.17 & 8.49 & 0.05 & 9.03 & 0.03 & $89.5^{* *}$ & 0.03 & 63.1** \\
\hline REs & 0.61 & & 7.53 & & 10.1 & & 27.5 & & 38.1 & & 7.40 & & 1.94 & & 4.61 & & 4.73 & \\
\hline
\end{tabular}

** Significant at the 0.01 probability level.

+ Concentration is expressed on an oven-dried mass basis.

$\$$ The significance level is calculated for the difference of $\mathrm{La} / \mathrm{RE}$ ratios between data from $2 \mathrm{~d}$ before application $\left(n_{1}=4\right)$ and data from 6 or $57 \mathrm{~d}$ after application $\left(n_{2}=1\right)$.

$\S$ Data is expressed as the mean of four plots in plot experiment.

The applied exogenous REs concentrations were 1 to $20 \mathrm{mg} \mathrm{REs} \mathrm{kg}^{-1}$ of soil, which correspond to 0.4 to $7 \%$ of REs in pot soil $\left(275.7 \mathrm{~g} \mathrm{~kg}^{-1}\right.$, Table 2$)$. At background conditions, the concentration of water-soluble REs in soil solution was only several parts per billion (Lu et al., 1997), while REs in the mixture (in forms of nitrates) were water soluble. Therefore, the increased concentration ratio after application of the REs mixture should be an indication that the plant accumulated REs from the applied REs mixture rather than from soil. When exogenous REs were present, concentration ratios of individual REs were more closely related to concentrations in the REs mixture than those in soil. For example, the concentration ratio for Ce was less expressed in comparison with that of La. The concentration ratio for plant leaves was not dose-dependent and therefore no accumulation could be expected when dose levels were less than $20 \mathrm{mg} \mathrm{REs} \mathrm{kg}{ }^{-1}$ (Table 4).

The NOEC for the accumulation of REs in corn seedlings for the pot experiment should be $1 \mathrm{mg}$ REs kg-1 soil, according to the one-way ANOVA.

\section{Accumulation of Rare Earth Elements in Different Parts of Corn in the Plot Experiment}

In the plot experiment, the lowest treatment (i.e., 16 $\mathrm{mg} \mathrm{REs} \mathrm{m}^{-2}$ ) followed the similar dosage used in farming practices and the REs mixture was applied in the way of foliage dressing. Figure 2 shows the dose-dependent accumulation of REs in the different parts of corn. The time-dependent variation in concentration of individual REs and La to RE ratios in the different parts of plant are shown in Tables 7 to 10 .

Before the application, concentrations of REs in plant roots and stems (Tables 5 and 6 ) in the pot experiment were obviously higher than those in the plot experiment (Tables 8 and $9 ;-2 \mathrm{~d}$ ). The large difference could be mainly due to the different RE concentrations in soils (Table 2). The RE concentration in pot soil $(275 \mathrm{mg}$ REs $\left.\mathrm{kg}^{-1}\right)$ was much higher than that in plot soil (150 mg REs $\mathrm{kg}^{-1}$ ); this should have forced more REs to accumulate in plant roots and stems from pot soil. The concentration difference between pot and plot experi-

Table 8. Concentration $\dagger$ and La to rare earth element (RE) ratio in corn stem before and after applying different doses of REs in the plot experiment.

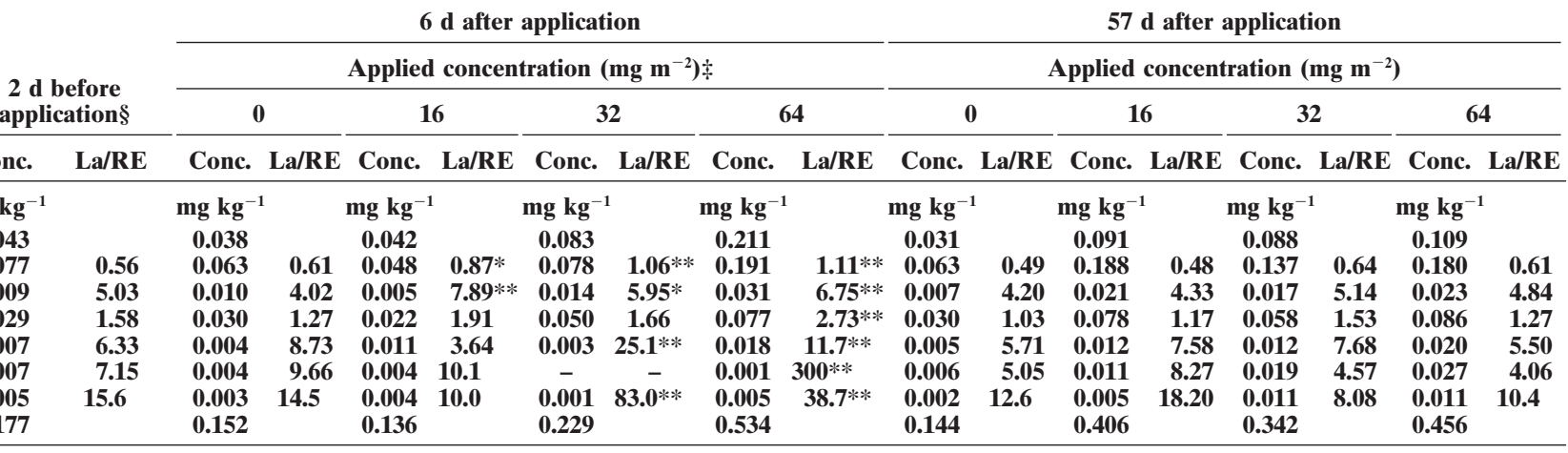

*, ** Significant at the 0.05 and 0.01 probability levels, respectively.

$\dagger$ Concentration is expressed on an oven-dried mass basis.

+ The significance level is calculated for the difference of $\mathrm{La} / \mathrm{RE}$ ratios between data from $2 \mathrm{~d}$ before application $\left(n_{1}=4\right)$ and data from 6 or $57 \mathrm{~d}$ after application $\left(n_{2}=1\right)$.

$\S$ Data is expressed as the mean of four plots in plot experiment. 
Table 9. Concentration $\dagger$ and La to rare earth element (RE) ratio in corn root before and after applying different doses of REs in the plot experiment.

\begin{tabular}{|c|c|c|c|c|c|c|c|c|c|c|c|c|c|c|c|c|c|c|}
\hline \multirow[b]{4}{*}{ RE } & & & \multicolumn{8}{|c|}{$6 \mathrm{~d}$ after application } & \multicolumn{8}{|c|}{$57 \mathrm{~d}$ after application } \\
\hline & \multirow{2}{*}{\multicolumn{2}{|c|}{$\begin{array}{c}2 \text { d before } \\
\text { application } \S\end{array}$}} & \multicolumn{8}{|c|}{ Applied $\mathbf{R E}$ concentration $\left(\mathrm{mg} \mathrm{m}^{-2}\right) \ddagger$} & \multicolumn{8}{|c|}{ Applied RE concentration $\left(\mathrm{mg} \mathrm{m}^{-2}\right)$} \\
\hline & & & \multicolumn{2}{|c|}{$\mathbf{0}$} & \multicolumn{2}{|c|}{16} & \multicolumn{2}{|c|}{32} & \multicolumn{2}{|r|}{64} & \multicolumn{2}{|c|}{$\mathbf{0}$} & \multicolumn{2}{|c|}{16} & \multicolumn{2}{|c|}{32} & \multicolumn{2}{|c|}{64} \\
\hline & Conc. & $\mathbf{L a} / \mathbf{R E}$ & Conc. & $\mathbf{L a} / \mathbf{R E}$ & Conc. & $\mathbf{L a} / \mathbf{R E}$ & Conc. & $\mathbf{L a} / \mathbf{R E}$ & Conc. & $\mathbf{L a} / \mathbf{R E}$ & Conc. & $\mathbf{L a} / \mathbf{R E}$ & Conc. & $\mathbf{L a} / \mathbf{R E}$ & Conc. & $\mathbf{L a} / \mathbf{R E}$ & Conc. & $\mathbf{L a} / \mathbf{R}$ \\
\hline & $\mathbf{m g ~ k g}^{-1}$ & & $\mathbf{m g ~ k g}^{-1}$ & & $\mathrm{mg} \mathrm{kg}^{-1}$ & & $\mathbf{m g ~ k g}^{-1}$ & & $\mathbf{m g ~ k g}^{-1}$ & & $\mathbf{m g ~ k g}^{-1}$ & & $\mathbf{m g ~ k g}^{-1}$ & & $\mathbf{m g ~ k g}^{-1}$ & & $\mathrm{mg} \mathrm{kg}^{-1}$ & \\
\hline $\begin{array}{l}\text { La } \\
\text { Ce }\end{array}$ & 0.71 & 0.50 & 1.07 & & $\begin{array}{l}1.24 \\
2.71\end{array}$ & & 1.02 & & $\begin{array}{l}18.51 \\
10.04\end{array}$ & & 1.89 & & 3.94 & & 5.03 & & 3.46 & \\
\hline Pr & 0.17 & 4 & 0. & 4.15 & $\begin{array}{ll}2.71 \\
0.28\end{array}$ & $\begin{array}{l}0.40 \\
4.44\end{array}$ & $\begin{array}{l}1.90 \\
0.23\end{array}$ & $\begin{array}{l}0.34 \\
4.37\end{array}$ & $\begin{array}{l}10 . \\
3 .\end{array}$ & $\begin{array}{l}1.84 * \\
5.36 * *\end{array}$ & $\begin{array}{l}4.05 \\
0.46\end{array}$ & $\begin{array}{l}0.47 \\
4.16\end{array}$ & $\begin{array}{l}7.79 \\
0.97\end{array}$ & $\begin{array}{l}0.51 \\
4.06\end{array}$ & $\begin{array}{c}10.1 \\
1.23\end{array}$ & $\begin{array}{l}0.50 \\
4.09\end{array}$ & $\begin{array}{l}7.01 \\
0.87\end{array}$ & 0.4 \\
\hline Nd & 0.79 & 1.04 & 0.97 & 1.10 & 1.05 & 1.19 & 0.75 & 1.37 & 5.19 & $3.57 * *$ & 1.73 & 1.09 & 3.23 & 1.2 & 4.47 & 1. & 2.84 & 1.2 \\
\hline Sm & 0.14 & 5.16 & 0.16 & 6.64 & 0.21 & 5.81 & 0.19 & 5.44 & 0.51 & $36.2 *$ & 0.34 & 5.55 & 0.61 & 6.45 & 0.87 & 5. & 0.58 & 5.9 \\
\hline Gd & 0.13 & 5.65 & 0.1 & 5.70 & 0.21 & 6.07 & 0.15 & 6.78 & 0.40 & $46.6^{* * *}$ & 0.3 & 5.92 & 0.62 & 6.37 & 0.74 & 6.75 & 0.51 & 6.78 \\
\hline Dy & 0.09 & 7.79 & 0.12 & 9.22 & 0.16 & 7.59 & 0.11 & 9.09 & 0.01 & $1637 * *$ & 0.19 & 9.94 & 0.40 & 9.82 & 0.53 & 9.43 & 0.34 & 10.1 \\
\hline REs & 3.55 & & 4.88 & & 5.86 & & 4.35 & & 38.1 & & 8.98 & & 17.6 & & 22.9 & & 15.6 & \\
\hline
\end{tabular}

** Significant at the 0.01 probability level.

$\dagger$ Concentration is expressed on an oven-dried mass basis.

$\$$ The significance level is calculated for the difference of $\mathrm{La} / \mathrm{RE}$ ratios between data from $2 \mathrm{~d}$ before application $\left(n_{1}=4\right)$ and data from 6 or $57 \mathrm{~d}$ after application $\left(n_{2}=1\right)$.

$\S$ Data is expressed as the mean of four plots in plot experiment.

ments also may be caused by different sampling strategies. The plant was sampled at the 25th day in the pot while it was first sampled (-2 d) after $90 \mathrm{~d}$ of growth in the plot experiment. As shown in the plot experiment, concentrations of REs in plant leaves increased during the plant shooting period (from $0.61 \mathrm{mg} \mathrm{REs} \mathrm{kg}^{-1}$ at

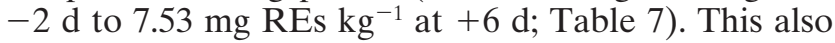
may explain the difference between the RE concentration in plant leaves in the pot experiment $(0.27 \mathrm{mg}$ REs $\left.\mathrm{kg}^{-1}\right)$ from that in the plot experiment $(0.61 \mathrm{mg}$ REs $\mathrm{kg}^{-1}$ ) for the control. The increased leaf concentration of REs in the control was probably not due to the influence of foliage dressing of the REs mixture in the neighboring treatment plots, because their corresponding $\mathrm{La}$ to $\mathrm{RE}$ ratios were relatively constant and were similar to those in soil (Table 7). Further studies should be done on RE accumulation in different plant growth periods.

After RE application $(+6 \mathrm{~d})$, especially when the doses were higher than $32 \mathrm{mg} \mathrm{m}^{-2}$, RE concentrations increased in the different parts of the plant (Fig. 2). An increase of RE concentrations in plant leaves could be the results of foliage dressing of the REs mixture, for which the applied REs were irreversibly fixed and could not be removed by washing. Increased RE concentrations in plant stems and roots could result from the translocation of REs from plant leaves to stems, at dos-

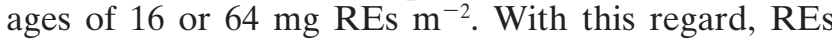
show a very similar to heavy metals, that is, an exclusion mechanism where plants avoid an excessive uptake, translocation, and accumulation, as well as a sequestration mechanism where plants accumulate metals at elevated soil concentrations (Baker, 1981). It should be noticed that higher RE concentrations in plant roots also could be the consequence of a reverse translocation pathway along with the stimulation effect to absorb more REs (unpublished data). The translocation of REs in plant tissues may be regarded as a detoxification mechanism. When the applied dose was $16 \mathrm{mg} \mathrm{REs} \mathrm{m}^{-2}$, the concentration differences in corn leaves, roots, and stems between the control group and the treatments were not obvious. We can estimate that the lowest observed effect concentration (LOEC) regarding accumulation of REs at the sixth day was about $32 \mathrm{mg} \mathrm{REs} \mathrm{m}^{-2}$.

At the 57th day, no dose-dependent accumulation of REs in plant leaves, flowers, and grain could be observed (Fig. 2) but RE concentrations in plant roots and

Table 10. Concentration $\dagger$ and La to rare earth element (RE) ratio in corn grain and flower after applying different doses of $\mathrm{REs}$ in the plot experiment.

\begin{tabular}{|c|c|c|c|c|c|c|c|c|c|c|c|c|c|c|c|c|}
\hline \multirow[b]{4}{*}{$\mathbf{R E}$} & \multicolumn{8}{|c|}{ Grain } & \multicolumn{8}{|c|}{ Flower } \\
\hline & \multicolumn{8}{|c|}{ Applied RE concentration $\left(\mathrm{mg} \mathrm{m}^{-2}\right) \ddagger$} & \multicolumn{8}{|c|}{ Applied $\mathrm{RE}$ concentration $\left(\mathrm{mg} \mathrm{m}^{-2}\right)$} \\
\hline & \multicolumn{2}{|c|}{$\mathbf{0}$} & \multicolumn{2}{|c|}{16} & \multicolumn{2}{|c|}{32} & \multicolumn{2}{|c|}{64} & \multicolumn{2}{|c|}{ 0 } & \multicolumn{2}{|c|}{16} & \multicolumn{2}{|c|}{32} & \multicolumn{2}{|c|}{64} \\
\hline & Conc. & $\mathbf{L a} / \mathbf{R E}$ & Conc. & $\mathbf{L a} / \mathbf{R E}$ & Conc. & $\mathbf{L a} / \mathbf{R E}$ & Conc. & $\mathbf{L a} / \mathbf{R E}$ & Conc. & $\mathbf{L a} / \mathbf{R E}$ & Conc. & $\mathbf{L a} / \mathbf{R E}$ & Conc. & $\mathbf{L a} / \mathbf{R E}$ & Conc. & $\mathbf{L a} / \mathbf{R E}$ \\
\hline & $\mathrm{mg} \mathrm{kg}^{-1}$ & & $\mathbf{m g ~ k g} \mathbf{~}^{-1}$ & & $\mathbf{m g ~ k g}{ }^{-1}$ & & $\mathbf{m g} \mathbf{k g}^{-1}$ & & $\mathbf{m g ~ k g ^ { - 1 }}$ & & $\mathbf{m g ~ k g}^{-1}$ & & $\mathbf{m g ~ k g}^{-1}$ & & $\mathbf{m g ~ k g ^ { - 1 }}$ & \\
\hline $\mathbf{L a}$ & 0.017 & & 0.019 & & 0.022 & & 0.08 & & 0.378 & & 0.493 & & 0.374 & & 0.492 & \\
\hline $\mathrm{Ce}$ & 0.029 & 0.40 & 0.028 & 0.55 & 0.041 & 0.69 & 0.19 & 0.57 & 0.763 & 0.47 & 1.004 & 0.48 & 0.773 & 0.49 & 1.055 & 0.50 \\
\hline Pr & 0.004 & 3.75 & 0.004 & 4.88 & 0.005 & 4.52 & 0.02 & 4.13 & 0.089 & 4.21 & 0.105 & 4.11 & 0.091 & 4.70 & 0.117 & 4.25 \\
\hline Nd & 0.010 & 0.88 & 0.021 & 1.48 & 0.015 & 0.93 & 0.09 & 1.60 & 0.314 & 1.12 & 0.447 & 1.01 & 0.370 & 1.10 & 0.438 & 1.21 \\
\hline Sm & 0.005 & 4.63 & 0.000 & 7.06 & 0.003 & - & 0.02 & 3.51 & 0.076 & 6.41 & 0.098 & 5.09 & 0.073 & 5.03 & 0.077 & 5.00 \\
\hline Gd & 0.001 & 3.31 & 0.003 & 7.82 & 0.003 & 6.11 & 0.02 & 15.5 & 0.050 & 6.37 & 0.055 & 6.95 & 0.054 & 9.03 & 0.048 & 7.49 \\
\hline Dy & 0.001 & 6.48 & 0.001 & 5.85 & 0.004 & 18.3 & 0.01 & 23.2 & 0.033 & 10.2 & 0.057 & 8.59 & 0.044 & 8.70 & 0.048 & 11.54 \\
\hline REs & 0.07 & & 0.07 & & 0.09 & & 0.43 & & 1.70 & & 2.26 & & 1.78 & & 2.30 & \\
\hline
\end{tabular}

$\dagger$ Concentration is expressed on an oven-dried mass basis.

$\$$ The significance level is calculated for the difference of La/RE ratios between data from $2 \mathrm{~d}$ before application $\left(n_{1}=4\right)$ and data from 6 or $57 \mathrm{~d}$ after application $\left(n_{2}=1\right)$. 
stems increased in comparison with those measured in the control plot. Table 10 shows that concentrations of REs in the edible part of corn (grain) were lower than $0.09 \mathrm{mg} \mathrm{REs} \mathrm{kg}{ }^{-1}$ and shows no dose-dependent accumulation when doses of REs were below $32 \mathrm{mg} \mathrm{m}^{-2}$. This result supports the field observation (Liu et al., 1997b) that no increase of RE concentrations was observed when the REs mixture is applied by the way of foliage dressing of $16 \mathrm{mg}$ REs $\mathrm{m}^{-2} \mathrm{a}^{-1}$ for a period of $12 \mathrm{yr}$. In their report, no increase of RE concentration in corn grain could be found, while RE concentrations in other parts of corn were obviously higher after application of the REs mixture. The concentration of REs in naturally grown corn grain from different provinces of China ranges from 0.04 to $0.30 \mathrm{mg} \mathrm{REs} \mathrm{\textrm {kg } ^ { - 1 }}(\mathrm{Ni}$, 1995), therefore application of the REs mixture at the present dose level should be safe for human and animal consumption considering the food chain processes.

The incorporation of exogenous REs into plant tissue at the sixth and 57th days of application could be verified by the ratios of La to RE in the different parts of corn, as shown in Tables 7 to 10. At the sixth day, an obvious augmentation in the ratios of La to RE in corn leaves and stems could be observed and the increase depended on the applied doses (Tables 7 and 8). Lanthanum to $\mathrm{RE}$ ratios for plant roots in the 16 and $32 \mathrm{mg}$ REs $\mathrm{m}^{-2}$ treatments were not significantly different from the control, but they obviously increased when treated with $64 \mathrm{mg} \mathrm{REs} \mathrm{m}^{-2}$ (Table 9). Since the exogenous REs were applied to plant leaves, the result indicates the reversed translocation of exogenous REs from leaf to stem (Table 8) and even to root at higher doses (Table 9). While RE concentrations in plant leaves show no increase at the day of harvest in comparison with control (Fig. 2), La to RE ratios for treatments of 32 and 64 mg REs $\mathrm{m}^{-2}$ were still higher than the control. By examining the data of Table 7, one can find that the concentrations of individual REs and REs in plant leaves at the 57th day simply resulted from the dilution of concentrations at the sixth day, probably because of the normal biomass increase (from $11 \mathrm{~g}$ per plant at the sixth day to $57 \mathrm{~g}$ per plant at the 57 th day). This result indicates that the REs remaining in corn leaves at the 57th day originated mostly from the REs mixture, similar to the observation from the pot experiment. Ratios of La to $\mathrm{RE}$ for other parts of the plant at the 57th day were not significantly different from the control group or from those of plot soils (Tables 9 and 10). Based on concentration and fingerprinting analysis for plant stem, root, flower and grain, a homeostatic regulation mechanism in plants against an excessive uptake of REs can be suggested.

\section{CONCLUSIONS}

The present study suggests a dose-dependent accumulation of REs in the different parts of corn when the dosage is higher than $1 \mathrm{mg} \mathrm{REs} \mathrm{kg}{ }^{-1}$ of soil in the pot experiment, or $32 \mathrm{mg} \mathrm{REs} \mathrm{m}^{-2}$ in the plot experiment. In the plot experiment, the accumulation effect could be observed only shortly after application and there was no observed RE accumulation in the different parts of corn at the day of harvest, when the applied REs mixture

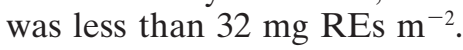

We can conclude that the corn shows no preference on the tested individual REs. The results of the concentration and fingerprinting analyses indicate the incorporation of exogenous REs in the plant and a translocation process of REs from plant root to leaf when REs are applied to soil or from leaf to root when applied to leaves. A homeostatic regulation mechanism for excessive uptake of REs in plants is suggested to regulate the concentrations of REs in plant.

\section{ACKNOWLEDGMENTS}

This work was supported by China National Science Foundation (29890280-2-3) and the Research Center for Eco-Environmental Sciences (RCEES-KIP-9901). We are grateful for the kindness of Prof. Nelson Belzile from Laurentian University, Canada for revising the English.

\section{REFERENCES}

Asher, C.J. 1991. Beneficial elements, functional nutrients and possible new essential elements. p. 703-723. In J.J. Mortvedt, F.R. Cox, L.M. Shuman, and R.M. Welch (ed.) Micronutrients in agriculture. 2nd ed. SSSA, Madison, WI.

Baker, A.J.M. 1981. Accumulation and excluders-Strategies in the response of plant to heavy metals. J. Plant Nutr. 3:643-654.

Boger, M., Y.H.M. Van Erp, and P. Eichner. 1997. Assessment of the potential toxicity of lanthanum for aquatic organism. p. 14-18. In R. Guicherit and W. Zhu (ed.) Proc. of the 2nd Sino-Dutch Workshop on the Environ. Behavior and Ecotoxicology of Rare Earth Elements and Heavy Metals. Oct. 1997. TNO Publ., La Delft, the Netherlands.

Brown, P.H., A.H. Rathjen, R.D. Graham, and D.E. Tribe. 1990. Rare earth elements in biological systems. p. 423-452. In K.A. Gschneidner, Jr. and L. Eyring (ed.) Handbook on the physic and chemistry of rare earth. Vol. 13. Elsevier Science Publ., Amsterdam, the Netherlands.

Chang, J. 1991. Effects of lanthanum on the permeability of root plasmalemma and the absorption and accumulation of nutrients in rice and wheat. Plant Physiol. Commun. 27:17-21.

Dong, P., Z. Wu, L. Xu, and X. Gao. 1992. Studies on the effects of rare earth elements on the increase of yield in agriculture: Rare earth absorption by cucumber roots and the effect on root exudation. J. Chin. Rare Earth Soc. 10:373-376.

Guo, B. 1988. Rare earth in agriculture. China Agric. Sci. and Technol. Press, Beijing.

Henderson, P. 1984. General geochemical properties and abundance of the rare earth elements. p. 1-32. In P. Henderson (ed.) Rare earth element geochemistry. Elsevier Science Publ., Amsterdam, the Netherlands.

Ichihashi, H., M. Hideyoshi, and T. Ryo. 1992. Rare earth elements in naturally grown plants in relation to their variation in soils. Environ. Pollut. 76:157-162.

Jackson, N. 1985. Rare earth report on a visit to the republic of China by an Australian delegation, 9-24 Sept. 1985. Dep. of Sci., Canberra, Australia.

Lao, X., C. Liu, S. Yang, X. Li, Y. Ma, and W. Wang. 1996. Rare earth absorption and distribution of maize plant. Chin. Bull. Bot. 13:59-61.

Liu, P., Y. Li, T. Ju, and M. Zhang. 1997a. Studies on the absorption and distribution of rare earth elements in soybean. Acta Agric. Boreali-occidentalis Sinica 6(2):58-60.

Liu, S., L. Wang, and S. Zhang. 1997b. Effect of long-term foliagedressing rare earth elements on their distribution, accumulation and transportation in soil-spring wheat system. Chin. J. Appl. Ecol. 8(1):55-58.

Liu, S., Y. Wang, S. Zhang, L. Wang, H. Qu, J. Sun, H. Chen, X. Gao, and F. Guo. 1997c. Effect of long-term (12 years) application 
on content and distribution of rare earth element in spring wheat and soil. Acta Ecol. Sinica 17(5):483-487.

Lu, P., Z. Wang, W. Wang, S. Yang, and A. Peng. 1997. Concentration distribution of rare earth elements in rainwater, surface runoff, atmosphere and soil in experimental plots and influences of RE. J. Chin. Rare Earth Soc. 15(2):155-159.

Ni, J. 1995. Distribution of rare earth elements in Chinese plants. p. 73-89. In J. Ni (ed.) The bioinorganic chemistry of rare earth elements. China Science Press, Beijing.

OECD. 1984. Guideline for testing of chemicals. 208. Terrestrial plant growth test. OECD, Brussels, Belgium.

Peng, A., and Z. Wang. 1995. Research progress in environmental chemistry of rare earth elements. Chin. J. Environ. Chem. 3(4): 22-32.

Qi, T., P. Liu, C. Song, and X. Wang. 1984. Studies on the absorption, transfer and distribution of rare earth elements in plants. J. Chin. Rare Earth Soc. 2(1):95-98.

SPSS. 1999. SPSS Version 9.0. SPSS, Chicago, IL.

Sun, J., and F. Li. 1990. The initial studies on lanthanum distribution in soybean seedling after treating root with rare earth elements. Rare Earth 11(3):32-34.

Todorovsky, D.S., L. Minkova, and P.B. Dariena. 1997. Effect of the application of superphosphate on rare earth element content in the soil. Sci. Total. Environ. 203:13-16.

Volkh, A.A., A.V. Gorbunov, B.A. Revich, M.V. Frontasyeva, and
C.S. Pal. 1990. Phosphorus fertilizer production as a source of rareearth elements pollution of the environment. Sci. Total. Environ. 95:141-148.

Wang, Z, P. Lu, and D. Liu. 1997. Initial assessment of the effects of rare earth elements on soil intigrity. p. 1-5. In R. Guicherit and W. Zhu (ed.) Proc. of the 2nd Sino-Dutch Workshop on the Environ. Behavior and Ecotoxicology of Rare Earth Elements and Heavy Metals. Oct. 1997. TNO Publ., La Delft, the Netherlands.

Wu, Z., J. Li, J. Xu, and S. Xin. 1985. The effect of nodulation and nitrogen fixation of soybean plants. p. 1505-1511. In Proc. Int Conf. on Rare Earth Development and Applications. China Science Press, Beijing.

Wu, Z., X. Tang, and C. Tsui. 1983. Studies on the effect of rare earth elements on the increasement of yield in agriculture. J. Chin. Rare Earth Soc. 1(1):70-75.

Xiong, B. 1995. Application of the rare earths in Chinese agriculture and their perspective development. p. 5-9. In Proc. of the Rare Earths in Agriculture Seminar. 20 Sept. 1995. Aust. Academy of Technol. Sci. and Eng., Victoria, Australia.

Zhang, S., and X.-Q. Shan. 1997. Determination of rare earth elements in soil by inductively coupled plasma mass spectrometry. Atomic Spectroscopy 18:140-144.

Zhang, Y., B. Xiong, Y. Hu, Q. Zhang, J. Wu, and J. Zhang. 1993. Effect of ten-year RE application on content and distribution of rare earth elements in spring wheat. Rare Earth 14(5):40-44.

\title{
Implementation of Sulfate Adsorption in the SAFE Model
}

\author{
Tamon Fumoto* and Harald Sverdrup
}

\begin{abstract}
An $\mathrm{SO}_{4}^{2-}$ adsorption submodel has been implemented in the dynamic soil chemistry model SAFE. The submodel calculates pH-dependent $\mathrm{SO}_{4}^{2-}$ and $\mathrm{H}^{+}$adsorption to the soil, as well as the net surface charge development due to uneven adsorption of $\mathrm{SO}_{4}^{2-}$ and $\mathrm{H}^{+}$, using the empirical equations derived from an electrostatic model (Extended Constant Capacitance Model, ECCM) of $\mathrm{SO}_{4}^{2-}$ adsorption. The resulting new SAFE model was applied on a roof experiment plot in the Norway spruce [Picea abies (L.) H. Karst.] stand at Solling, Germany, where atmospheric $S$ and $\mathbf{N}$ deposition was artificially reduced by the roof construction. The model performance was compared with the previous versions that used a $\mathrm{pH}$-independent Freudlich model of $\mathrm{SO}_{4}^{2-}$ adsorption or assumed no $\mathrm{SO}_{4}^{2-}$ adsorption. With the ECCM-based $\mathrm{SO}_{4}^{2-}$ adsorption submodel, SAFE simulated soil solution $\mathrm{SO}_{4}^{2-}$ concentration and base saturation better, in comparison with measured data, than with the previous $\mathrm{SO}_{4}^{2-}$ adsorption formulations. Through the model application, also, need of additional improvement was suggested, such as calibration of mass transfer coefficients.
\end{abstract}

$I^{\prime}$ $\mathrm{N}$ the modern industrialized era, terrestrial ecosystems are subject to effects of various anthropogenic environmental pollutants, such as acid depositions, ozone gas, and toxic organic and inorganic substances. Mathematical models are one of the potent means to assess the potential influence of the pollution on the

Department of Chemical Engineering II, Lund University, P.O. Box 124, S-221 00 Lund, Sweden. T. Fumoto, present address: National Institute of Agro-Environmental Sciences, Kannondai 3-1-1, Tsukuba, 305-8604 Japan. Received 12 Nov. 1999.*Corresponding author (tamon@ niaes.affrc.go.jp).

Published in J. Environ. Qual. 30:45-57 (2001). ecosystems and human beings and to build the optimal strategies of pollutant abatement and remediation.

Aiming at the simulation of the responses of terrestrial ecosystems against acid depositions, a considerable number of dynamic soil chemistry models have been developed in recent years, including MAGIC (Cosby et al., 1985), ILWAS (Gherini et al., 1985), MIDAS (Holmberg et al., 1989), SMART (De Vries et al., 1989), SAFE (Warfvinge et al., 1993), RESAM (De Vries et al., 1994), and PnET-CN/CHESS (Postek et al., 1995). These models have been mostly designed for and applied on European and North American ecosystems, but a drastic increase in $\mathrm{SO}_{\mathrm{x}}$ emissions is expected for Asian countries until the first half of the twenty-first century (Stockholm Environment Institute, 1998). Consequently, application of the dynamic soil chemistry models on Asian ecosystems will be required to assess the environmental effects of increased acid depositions.

Concerning the soil acidification-recovery processes, one of the distinct features of Asian ecosystems is the extensive occurrence of $\mathrm{SO}_{4}^{2-}$ adsorbing soils, such as Andisols, in which $\mathrm{SO}_{4}^{2-}$ adsorption capacity has a high correlation with the Al content in allophane and imogolite (Fumoto et al., 1996a,b). The molar $\mathrm{H}^{+}$to $\mathrm{SO}_{4}^{2-}$ adsorption ratio on soils and minerals is generally less than 2.0 and dependent on $\mathrm{pH}$ (Karltun, 1997; Persson and Lövgren, 1996; He et al., 1996), and the resulting net negative charge may affect the base cation dynamics in the soil. However, few of the current dynamic soil chemistry models simulate the $\mathrm{pH}$ dependency of $\mathrm{SO}_{4}^{2-}$ and $\mathrm{H}^{+}$

Abbreviations: ANC, acid neutralizing capacity; ECCM, Extended Constant Capacitance Model. 